\title{
Child psychiatry and the developmental perspective
}

\author{
Guilherme V. Polanczyk
}

Published online: 3 February 2012

(C) Springer-Verlag 2012

In 1963, J. Cotter Hirschberg, in a conference named "The basic functions of a child psychiatrist in any setting", highlighted that one of the several unique contributions which child psychiatrists may make in our work was the understanding of a symptom in the context of development [1]. Three years later, Lee Robins [2] published the landmark longitudinal study "Deviant children grown up", demonstrating the continuity between conduct problems in childhood and antisocial personality disorder in adulthood, and by that, clearly demonstrating to the mental health field the value of tracking people across the lifespan, since childhood, to understand psychopathology. In the following decades, Sroufe and Rutter [3], Garmezy [4], and Cicchetti [5] published influential papers that established the discipline of developmental psychopathology. In parallel, an upsurge of new technologies has unveiled the genome and the brain, paving the way to identify atypical neurodevelopmental processes underlying psychopathology. Today, a developmental perspective is still pivotal in our clinical work as child and adolescent psychiatrists, but not unique to us: a developmental perspective now shapes the current conceptualization and investigation of mental disorders, from those that are apparent in early childhood to senescence [6], and also the avenues to treat them [7].

Our field has benefited tremendously from investigations that took advantage of a developmental framework, and fortunately their number has been increasing dramatically over time. Several important examples have been

G. V. Polanczyk ( $\square)$

Department of Psychiatry, University of São Paulo Medical School, National Institute of Developmental Psychiatry for Children and Adolescents (INCT-CNPq), Rua Dr. Ovídio Pires de Campos 785, São Paulo, SP 05403-010, Brazil

e-mail: gvp@usp.br published in the European Child \& Adolescent Psychiatry in the past years, with emphasis on early predictors of later psychopathology [8, 9], continuity and discontinuity of psychopathology across development [10-13], risk and protective factors investigation [14], early intervention [15], and others approaches [16]. In this issue, we see two studies with this same perspective investigating the biological underpinnings of psychopathology.

The first study, by Walhovd and colleagues [17] from the University of Oslo, Norway, tested whether the dimensional nature of behavioral symptoms in childhood correlated with brain maturation. Built upon on the finds from Judith Rapoport, Philip Shaw and their team, who beautifully demonstrated that children with attention-deficit/hyperactivity disorder attained a maturational milestone (the peak of cortical thickness) later in comparison to control children [18], Walhovd and colleagues now tested cross-sectionally the association between cortical thickness and hyperactive, inattentive, and conduct symptoms in 107 healthy children from 8 to 19 years. The authors found no evidence of association between hyperactive and inattentive symptoms in healthy children and cortical thickness. Nevertheless, conduct symptoms were associated with cortical thickness controlling for age in left prefrontal and supramarginal areas. This association was being largely driven by younger children, where the interactions between conduct symptoms and age were reflected in regionally thinner frontal and temporal cortices bilaterally.

The second study, by Beitchman and colleagues [19] from the University of Toronto, Canada, tested the association between oxytocin genes and behavioral characteristics of children with antisocial behavior. Built upon on an extensive body of work that has demonstrated that oxytocin has important cognitive and behavioral effects, such as to facilitate social memory and afiliative behavior, which are 
impaired in disorders such as autism [20], Beitchman and colleagues now tested the association between six polymorphims on the oxytocin and oxytocin receptor genes and child aggression and callous-unemotional traits in 162 children with antisocial behavior compared to healthy adult controls. The authors found no polymorphism to be associated with aggressive behavior in the matched case-control analysis. Evaluating children with callous-unemotional trait, which reflect more severe emotional dysfunctions such as lack of empathy, lack of guilt, and shallow emotions, authors detected interesting results. The polymorphism rs237885 on the oxytocin receptor gene, and the haplotype consisting of this same polymorphism and also by rs2268493, were associated with significantly higher callous-unemotional trait in children with antisocial behavior. The haplotype analysis result was not significant when the sample was restricted to caucasians, but the single marker result was still significant, as well as when correction for multiple testing was applied.

The two studies published in this issue took advantage of relatively recent technologies-magnetic resonance imaging and genomic sequencing-to explore potential biological processes involved in the development of behavioral symptoms. The first study shows us that the presence of conduct symptoms even in children without a diagnosable mental disorder are reflected by impairment in the brain maturation. The second study shows us that oxytocin receptor gene is likely to be involved in the development of callous-unemotional trait. Their clinically oriented strategies of studying symptoms dimensionally and exploring a refined phenotype demonstrate how fruitful the dialogue between researchers and clinicians can be. New technologies that can deeper understand the brain, and consequently atypical neurodevelopmental processes, are now a reality. Genome-wide DNA and RNA analysis of human brain tissue and induced pluripotent stem cells are the two among several others with enormous potential. Their potential to impact their field, however, will also depend on a persistent dialogue among clinicians, clinical and basic investigators. As child and adolescent psychiatrists, our contribution is valuable and we shall work collaboratively and think innovatively to "open new avenues and challenge the wisdom of the day" [21].

\section{References}

1. Hirschberg JC (1966) The basic functions of a child psychiatrist in any setting. J Am Acad Child Psychiatry 5:360-366

2. Robins LN (1966) Deviant children grown up: a sociological and psychiatric study of sociopathic personality. MD Williams \& Wilkins, Baltimore
3. Sroufe LA, Rutter M (1984) The domain of developmental psychopathology. Child Dev 55:17-29

4. Garmezy N, Masten AS, Tellegen A (1984) The study of stress and competence in children: a building block for developmental psychopathology. Child Dev 55:97-111

5. Cicchetti D (1984) The emergence of developmental psychopathology. Child Dev 55:1-7

6. Salum GA, Polanczyk GV, Miguel EC, Rohde LA (2010) Effects of childhood development on late-life mental disorders. Curr Opin Psychiatry 23:498-503

7. Insel TR (2009) Disruptive insights in psychiatry: transforming a clinical discipline. J Clin Invest 119:700-705

8. Di Giunta L, Pastorelli C, Eisenberg N, Gerbino M, Castellani V, Bombi AS (2010) Developmental trajectories of physical aggression: prediction of overt and covert antisocial behaviors from self- and mothers' reports. Eur Child Adolesc Psychiatry 19:873-882

9. Lehti V, Sourander A, Klomek A et al. (2011) Childhood bullying as a predictor for becoming a teenage mother in Finland. Eur Child Adolesc Psychiatry 20:49-55

10. Groeben M, Perren S, Stadelmann S, von Klitzing K (2011) Emotional symptoms from kindergarten to middle childhood: associations with self- and other-oriented social skills. Eur Child Adolesc Psychiatry 20:3-15

11. Jepsen JR, Fagerlund B, Pagsberg AK, Christensen AM, Nordentoft M, Mortensen EL (2010) Deficient maturation of aspects of attention and executive functions in early onset schizophrenia. Eur Child Adolesc Psychiatry 19:773-786

12. Reef J, Diamantopoulou S, van Meurs I, Verhulst F, van der Ende J (2010) Predicting adult emotional and behavioral problems from externalizing problem trajectories in a 24-year longitudinal study. Eur Child Adolesc Psychiatry 19:577-585

13. Robbers SC, van Oort FV, Polderman TJ, et al. (2011) Trajectories of CBCL attention problems in childhood. Eur Child Adolesc Psychiatry 20:419-427

14. Flouri E, Tzavidis N, Kallis C (2010) Adverse life events, area socioeconomic disadvantage, and psychopathology and resilience in young children: the importance of risk factors' accumulation and protective factors' specificity. Eur Child Adolesc Psychiatry 19:535-546

15. McArdle P, Young R, Quibell T, Moseley D, Johnson R, LeCouteur A (2011) Early intervention for at risk children: 3-year follow-up. Eur Child Adolesc Psychiatry 20:111-120

16. Shelton KH, Collishaw S, Rice FJ, Harold GT, Thapar A (2011) Using a genetically informative design to examine the relationship between breastfeeding and childhood conduct problems. Eur Child Adolesc Psychiatry 20:571-579

17. Walhovd KB, Tamnes CK, Østby Y, Due-Tønnessen P, Fjell AM (2012) Normal variation in behavioral adjustment relates to regional differences in cortical thickness in children. Eur Child Adolesc Psychiatry 21. doi:10.1007/s00787-012-0241-5

18. Shaw P, Eckstrand K, Sharp W et al (2007) Attention-deficit/ hyperactivity disorder is characterized by a delay in cortical maturation. Proc Natl Acad Sci USA 104:19649-19654

19. Beitchman JH, Zai CC, Muir K, et al (2012) Childhood Aggression, callous-unemotional traits and oxytocin genes Eur Child Adolesc Psychiatry 21. doi:10.1007/s00787-012-0240-6

20. Insel TR, O'Brien DJ, Leckman JF (1999) Oxytocin, vasopressin, and autism: is there a connection? Biol Psychiatry 45:145-157

21. Rutter M (2010) Child and adolescent psychiatry: past scientific achievements and challenges for the future. Eur Child Adolesc Psychiatry 19:689-703 